\title{
Compostos bioativos em geleia de bocaiuva com maracujá
}

\section{Bioactive compounds in bocaiuva jelly with passion fruit}

Compuestos bioactivos en gelatina de bocaiuva con maracuyá

Roberta Serafim de Souza ${ }^{1}$ Jéssica Pereira Cuellar ${ }^{2}$ Juliana Rodrigues Donadon ${ }^{3}$ Rita de Cássia Avellaneda Guimarães ${ }^{4}$

${ }^{1}$ Mestranda pelo Programa de Pós-graduação em Saúde e Desenvolvimento na Região Centro-Oeste. Graduação em Nutrição pela Universidade Federal de Mato Grosso do Sul (UFMS). E-mail: robertaserafim06@gmail.com, Orcid: http://orcid.org/0000-0003-2538-6707

${ }^{2}$ Graduação em Nutrição pela Universidade Federal de Mato Grosso do Sul (UFMS). E-mail: jecuellar2@gmail.com, Orcid: http://orcid.org/0000-0002-7444-9818

${ }^{3}$ Doutora e mestre em Produção Vegetal pela Universidade Estadual Paulista "Júlio de Mesquita Filho" (UNESP), Jaboticabal. Graduada em Agronomia pela UNESP. Professora da Universidade Federal de Mato Grosso do Sul (UFMS), Campo Grande. E-mail: julianadonadon@yahoo.com.br, Orcid: http://orcid.org/0000-0003-3657-2206

${ }^{4}$ Doutora em Saúde e Desenvolvimento na Região Centro-Oeste pela Universidade Federal de Mato Grosso do Sul (UFMS). Mestre em Biotecnologia pela Universidade Católica Dom Bosco (UCDB), com sanduíche na Universidade Católica de Brasília (UCB). Graduada em Nutrição pela UCDB. Professora

Adjunta Nível III do curso de Nutrição da UFMS, e docente do quadro permanente do Programa de Pós-Graduação em Saúde e Desenvolvimento na

Região Centro-Oeste, da Faculdade de Medicina (FAMED) da UFMS. E-mail: ritaaguimaraes@gmail.com, Orcid: http://orcid.org/0000-0003-2538-6707 
Resumo: O aproveitamento de frutos no desenvolvimento de produtos visa inserir no mercado alimentos com um maior aporte de nutrientes, estimulando assim, hábitos de vida mais saudáveis. Os frutos do Cerrado possuem um grande potencial econômico e nutricional, entretanto se faz necessária a busca por alternativas para um maior aproveitamento e conservação desses frutos. Diante do exposto, o objetivo deste trabalho foi caracterizar quimicamente geleia de bocaiuva (Acrocomia aculeata) acrescida de maracujá (Passiflora edulis), por meio dos parâmetros: sólidos solúveis, acidez titulável, $\mathrm{pH}$, Aw, sólidos totais, fenóis totais, atividade antioxidante, taninos, carotenoides e ácido ascórbico. A polpa de bocaiuva utilizada na elaboração da geleia também foi caracterizada devido aos diferentes morfotipos encontrados no Estado de Mato Grosso do Sul. A geleia de bocaiuva com maracujá apresenta 106,01 $\mathrm{mg} \mathrm{g}^{-1}$ de fenóis

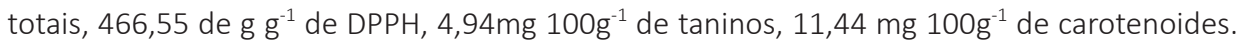
A polpa de bocaiuva apresenta 240,8 $\mathrm{mg} \mathrm{g}^{-1}$ de fenóis totais, 261,14 de $\mathrm{g} \mathrm{g}^{-1}$ de DPPH, 10,66

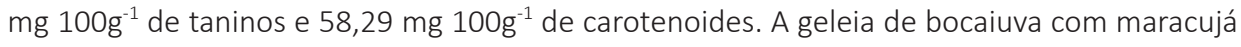
reteve os compostos considerados bioativos em sua composição, provenientes das polpas de bocaiuva e de maracujá.

Palavras-chave: Acrocomia aculeata; cerrado; compostos bioativos.

\begin{abstract}
The use of fruits in the development of products aims to insert in the market foods with a greater contribution of nutrients, thus stimulating, healthier life habits. The Cerrado fruits have great economic and nutritional potential, however, it is necessary to search for alternatives for a better use and conservation of these fruits. The objective of this work was to characterize the chemical composition of bocaiuva jelly (Acrocomia aculeata) and passion fruit (Passiflora edulis), using soluble solids, titratable acidity, $\mathrm{pH}, \mathrm{Aw}$, total solids, total phenols, antioxidant activity, tannins, carotenoids and ascorbic acid. The pulp of bocaiuva used in the elaboration of the jelly was also characterized due to the different morphotypes found in the State of Mato Grosso do Sul. The jelly of bocaiuva with passion fruit presents $106,01 \mathrm{mg} \mathrm{g}^{-1}$ of total phenols,

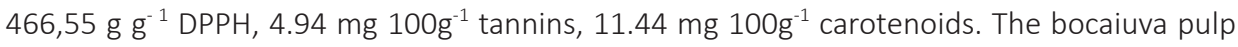

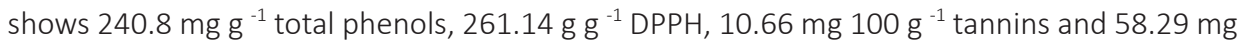
$100 \mathrm{~g}^{-1}$ carotenoids. The bocaiuva jelly with passion fruit retained the compounds considered bioactive in their composition, derived from the pulp of bocaiuva and passion fruit.
\end{abstract}

Keywords: Acrocomia aculeata; cerrado; bioactive compounds.

Resumen: El aprovechamiento de frutos en el desarrollo de productos busca insertar en el mercado alimentos con un mayor aporte de nutrientes, estimulando así, hábitos de vida más saludables. Los frutos del Cerrado poseen un gran potencial económico y nutricional, sin embargo, se hace necesaria la búsqueda de alternativas para un mayor aprovechamiento y conservación de estos frutos. En el presente trabajo se analizó la relación entre el peso de la muestra y el peso de la muestra, y el peso de la muestra, taninos, carotenoides y ácido ascórbico. La polla de bocayuva utilizada en la elaboración de la glaciación también fue caracterizada debido a los diferentes morfotipos encontrados en el Estado de Mato Grosso do Sul. La glaciación de bocayuva con maracuyá presenta 106,01 $\mathrm{mg} \mathrm{g}^{-1}$ de fenoles totales, 466,55 de $\mathrm{g} \mathrm{g}^{-1}$ de DPPH,

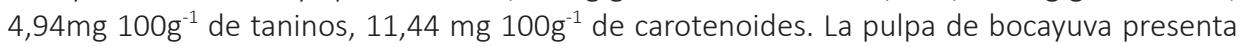
$240,8 \mathrm{mg} \mathrm{g}^{-1}$ de fenoles totales, 261,14 $\mathrm{de} \mathrm{g} \mathrm{g}^{-1}$ de DPPH, 10,66 mg $100 \mathrm{~g}^{-1}$ de taninos y 58,29 mg $100 \mathrm{~g}^{-1}$ de carotenoides. La jalea de bocaiuva con maracuyá retuvo los compuestos considerados bioactivos en su composición, provenientes de las pulpas de bocayuva y de maracuyá.

Palabras clave: Acrocomia aculeata; cerrado; compuestos bioactivos. 


\section{INTRODUÇÃO}

O Cerrado brasileiro está localizado na parte central do país e abrange uma área de mais de 200 milhões de hectares, o que corresponde a 1 1/4 de todo território nacional. Estima-se que o Cerrado brasileiro seja responsável por $1 / 3$ de toda a biodiversidade nacional. Além dos aspectos ambientais, 0 bioma tem grande importância social em que se verifica que comunidades sobrevivem de seus recursos naturais. Frutos comestíveis são regularmente consumidos pela população local e vendidos nos centros urbanos, como os frutos do pequi (Caryocar brasiliense), buriti (Mauritia flexuosa), mangaba (Hancornia speciosa), bocaiuva (Acrocomia aculeata) e as castanhas do baru (Dipteryx alata Vog).

A bocaiuva é um fruto nativo das florestas tropicais pertencente à família Arecaceae e à espécie Acrocomia aculeata. Essa palmeira é amplamente distribuída em todo o Cerrado brasileiro, principalmente nos Estados de Mato Grosso do Sul, Mato Grosso, São Paulo e Minas Gerais. Acrocomia aculeata é considerada uma planta rica em compostos antioxidantes, além disso, estudos associam potenciais antinflamatórios, antidiabéticos e diuréticos aos frutos.

Os frutos fornecem macronutrientes e micronutrientes, além dos compostos bioativos os quais produzem impacto significativo na manutenção da saúde. A bocaiuva também conhecida como macaúba apresenta componentes bioativos importantes para a dieta humana (BRESSAN et al., 2009), tais como ácido oleico, beta-caroteno e tocoferóis. A polpa da bocaiuva apresenta coloração amarelo alaranjado o que denota grande presença de carotenoides. Esses compostos são considerados precursores da vitamina A, que desempenha funções fisiológicas essenciais como: formação, proteção e regeneração da pele e das mucosas, aumento do sistema imune e auxilia na manutenção da visão.

O conhecimento da composição química dessas espécies é importante para desenvolver novos produtos por meio das etapas de processamento de polpa de frutos. Os frutos nativos ocupam lugar de destaque na região, pois muitos deles são comercializados e consumidos in natura ou beneficiados pelas indústrias caseiras, mas a maioria ainda é desconhecida. 
A elaboração de produtos com frutos nativos se mostra como alternativa no intuito de agregar valor aos frutos, possibilitando a geração de renda para extrativistas, e obter um produto rico nutricionalmente, beneficiando à saúde.

A geleia de fruta é o produto preparado com frutas, sucos ou extratos aquosos destas, podendo-se utilizar frutas inteiras, partes, ou pedaços de variadas formas, devendo ser misturados com açúcares, com ou sem adição de água, pectina, ácidos e outros ingredientes permitidos. Tal mistura será convenientemente concentrada até uma consistência semissólida adequada e, finalmente, acondicionada de forma a assegurar sua perfeita conservação. O processamento de geleia é interessante, pois exige poucos equipamentos e traz, como vantagens para o setor produtivo, o aproveitamento de frutas impróprias para a comercialização in natura, em compota ou desidratada. Também permite o uso do excedente da produção. Diante do exposto, este trabalho teve como objetivo caracterizar quimicamente geleia de bocaiuva com maracujá, quantificando os compostos bioativos.

\section{MATERIAL E MÉTODOS}

\subsection{Matéria-prima}

Os frutos de bocaiuva foram coletados na Região do Pantanal, nas proximidades do município de Corumbá, Mato Grosso do Sul, sendo previamente selecionados, situação na qual os frutos com rachaduras, sinais de deterioração, senescência e características sensoriais indesejáveis foram descartados. Em seguida, foram transportados à Unidade de Tecnologia de Alimentos e Saúde Pública (UTASP) da Universidade Federal de Mato Grosso do Sul (UFMS), onde passaram por mais um processo de seleção e descarte, além da higienização com hipoclorito a 200 $\mathrm{mg} \mathrm{L}^{-1}$ de cloro ativo por 10 minutos e enxaguados em água corrente; posteriormente foram dispostos sobre bancada de inox para a secagem da água superficial do fruto em temperatura ambiente e, por fim, inseridos em embalagens de polietileno de baixa densidade com dimensões de $25 \times 30 \mathrm{~cm}$, para congelamento em freezer $a-18$ ㄷ. Para a extração da polpa, foi realizado o descongelamento do fruto sob refrigeração. Com os frutos já descongelados, foi realizada a 
retirada da casca e despolpamento com o auxílio de facas inoxidáveis. Em seguida, houve a mistura das polpas dos frutos coletados em diferentes indivíduos, formando um blend, que subsequentemente foi congelada em sacos flexíveis de polietileno de baixa densidade, a $-18^{\circ} \mathrm{C}$, até o momento do desenvolvimento da geleia.

Os maracujás foram adquiridos em comércio local, transportados até a UTASP-UFMS, higienizados em solução de hipoclorito de sódio a $200 \mathrm{mgL}^{-1}$ e, em seguida, foram enxaguados em água corrente e despolpados com o auxílio de utensílios de aço inoxidável.

\subsection{Formulação da geleia}

Foi elaborada geleia extra de bocaiuva com maracujá cuja proporção de sacarose/fruta (combinação de bocaiuva com maracujá) é de $1 / 1$ (p/p). Para geleificação, adicionou-se $1 \%$ de pectina cítrica em relação à massa total de bocaiuva com maracujá, que foi preparada com $31 \%$ de polpa de bocaiuva e $69 \%$ de suco de maracujá. O suco de maracujá foi preparado com $60 \%$ de polpa integral de maracujá e $40 \%$ de água, homogeneizados em tacho aberto até ebulição. O suco foi peneirado para clarificação, e as sementes retidas na peneira foram separadas, e o resíduo restante, descartado. Da massa total de polpa de bocaiuva, 50\% foram submetidos à cocção com o suco de maracujá por 3 minutos. Após a cocção, o produto foi homogeneizado em liquidificador Philips 550 W. Em seguida, adicionou-se o restante da polpa picada de bocaiuva, em pedaços com dimensões de 0,5 cm x 0,5 $\mathrm{cm}$, aproximadamente, para obtenção da base da geleia.

A geleia foi preparada utilizando-se $50 \%$ de açúcar cristal (sacarose), $50 \%$ da base da geleia, $1 \%$ de pectina em relação à massa total e $5 \%$ de sementes de maracujá em relação à base da geleia. A pectina em pó foi homogeneizada com o açúcar, que foi adicionado aos poucos durante a cocção em tacho aberto. A geleia foi concentrada até aproximadamente $67,5^{\circ}$ Brix. A proporção de suco de maracujá foi definida previamente para o ajuste do $\mathrm{pH}$ para aproximadamente 3,3.

A geleia foi envasada a quente em embalagens de vidro com capacidade para $250 \mathrm{~g}$, submetidas previamente à esterilização comercial em 
água em ebulição por 15 minutos. A seguir, as geleias foram resfriadas em temperatura ambiente.

Figura 1 - Fluxograma de Processamento da geleia

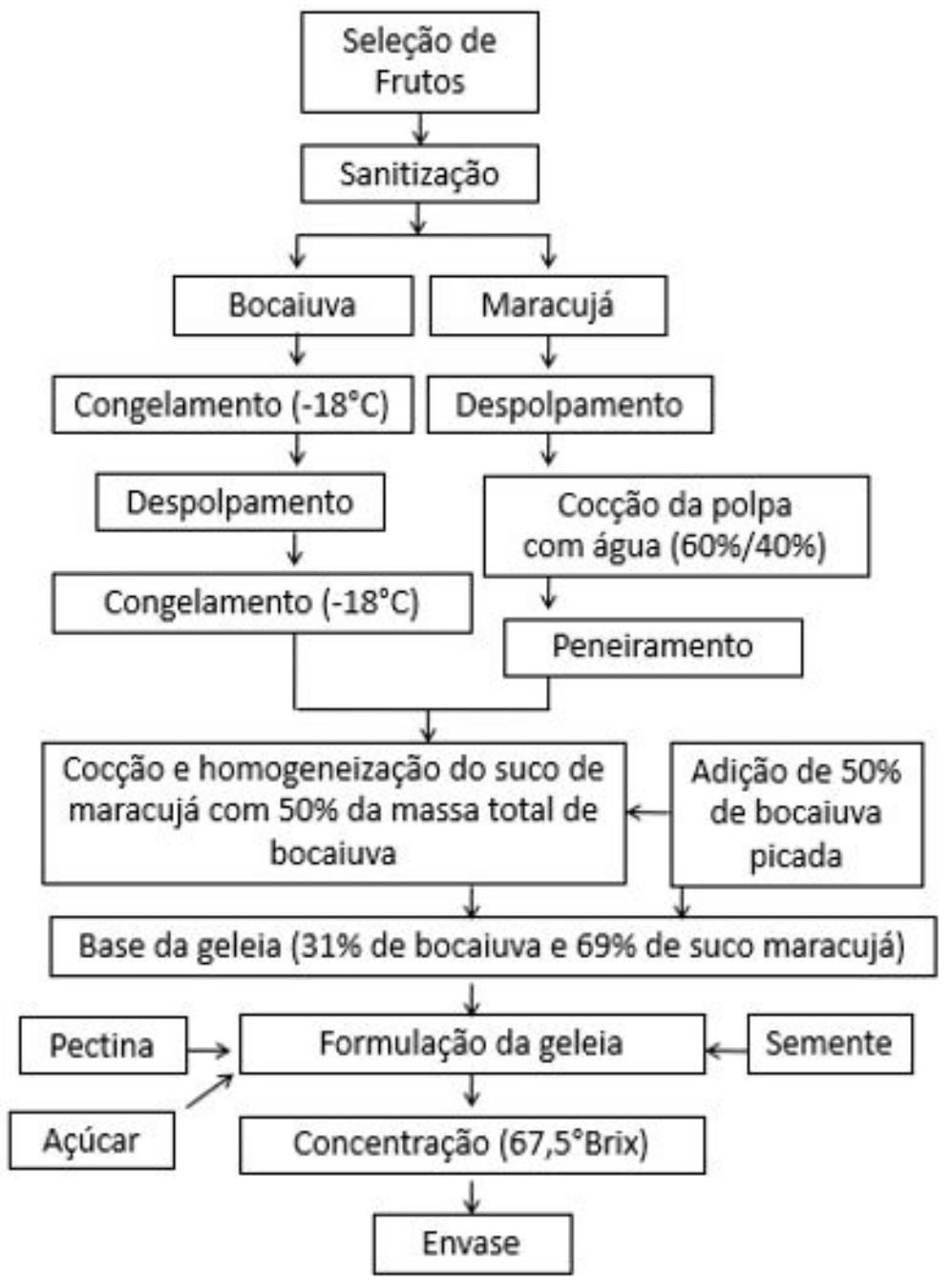

Fonte: Elaborado pelo autor, 2017 


\subsection{Análises físico-químicas}

A polpa de bocaiuva (blend) e a geleia foram caracterizadas em três repetições quanto aos teores de acidez titulável, $\mathrm{pH}$, sólidos totais, e quanto aos compostos considerados bioativos, fenóis totais, taninos, carotenoides, ácido ascórbico e atividade antioxidante. A geleia também foi caracterizada quanto aos teores de sólidos solúveis e atividade de água. A polpa de bocaiuva foi caracterizada devido à grande variabilidade de morfotipos e espécies no Estado de Mato Grosso do Sul.

A acidez titulável (AT) foi determinada por titulação com solução padronizada de hidróxido de sódio 0,1N (BRASIL, 2006 ). O pH foi avaliado por meio de potenciômetro calibrado com tampão de pH 7,0 e 4,0, segundo metodologia da AOAC (1997), e os teores de sólidos totais em estufa a $105^{\circ} \mathrm{C}$ até obtenção de uma massa constante. Os teores de sólidos solúveis (SS), expressos em ${ }^{\circ}$ Brix, foram determinados por meio do refratômetro digital. A atividade de água $\left(A_{w}\right)$ foi quantificada por meio do equipamento HydropalmModelAw1.

Os fenóis totais e a capacidade antioxidante foram avaliados em extratos hidrocetônicos (70\% de acetona) na polpa in natura e geleia (ROESLER et al. 2007). Os extratos foram submetidos à reação colorimétrica de determinação de compostos fenólicos conforme Swain e Hills (1959). $\mathrm{Na}$ determinação da capacidade antioxidante, o valor de $\mathrm{IC}_{50}$ foi definido como a concentração final do extrato integral requerido para decrescer a concentração inicial de DDPH em 50\%.

Os taninos foram determinados nos frutos in natura e na geleia por método colorimétrico, baseado na redução de fosfotungstomolibidico (Folin-Dennis), e o extrato também foi preparado de acordo com Zenebon et al. (2008). O teor de ácido ascórbico foi quantificado por meio de método titulométrico, usando 2,6 de clorofenolindofenol de sódio a 0,1\% (RANGANA, 1977 ) e o teor de carotenoides totais foi quantificado segundo Kimura e Rodriguez-Amaya (2001). 


\section{RESULTADOS E DISCUSSÃO}

A caracterização química da polpa e da geleia de bocaiuva com maracujá está descrita na Tabela 1.

Tabela 1 - Caracterização química de geleia de bocaiuva com maracujá. Resultados obtidos a partir de média e desvio padrão

\begin{tabular}{lccccc}
\hline \multicolumn{1}{c}{ Amostras } & $\begin{array}{c}\text { Sólidos } \\
\text { solúveis } \\
\text { ('Brix) }\end{array}$ & $\begin{array}{c}\text { Acidez Titulável } \\
\text { (g de ácido } \\
\text { cítrico } / \mathbf{1 0 0 g})\end{array}$ & $\mathbf{p H}$ & $\begin{array}{c}\text { Atividade de } \\
\text { água }\end{array}$ & $\begin{array}{c}\text { Sólidos } \\
\text { Totais } \\
\text { (g/100g) }\end{array}$ \\
\hline $\begin{array}{l}\text { Polpa de } \\
\text { bocaiuva }\end{array}$ & - & $0,33 \pm 0,002$ & $5,75 \pm 0$ & - & $30,0 \pm 0,039$ \\
$\begin{array}{l}\text { Geleia de } \\
\text { bocaiuva com } \\
\text { maracujá }\end{array}$ & $65,37 \pm 3,26$ & $0,96 \mathrm{~g} \pm 0,004$ & $3,7 \pm 0,016$ & $0,84 \pm 0,021$ & $52,56 \pm 0,051$ \\
\hline
\end{tabular}

*Dados apresentados em média \pm desvio-padrão.

Fonte: Elaborada pelo autor.

A geleia de bocaiuva apresentou $65,37^{\circ}$ Brix, valor este que se enquadra dentro das indicações das Normas Técnicas Relativas a Alimentos e Bebidas n. 12, em que o teor de sólidos solúveis para geleias é de no mínimo $62^{\circ}$ Brix e o ideal de $67,5^{\circ}$ Brix (BRASIL, 1978). De acordo com Viana et al. (2012), valores acima de $71^{\circ}$ Brix podem levar à cristalização da geleia. Para Pereira et al. (2011), a cristalização excessiva pode dar origem a um produto com textura arenosa, o que não é uma característica satisfatória para geleias. Diante disso, podemos considerar que o valor de sólidos solúveis encontrado neste trabalho foi satisfatório. Garcia et al. (2017) encontrou $62^{\circ}$ Brix em geleia de buriti (Mauritia flexuosa), enquanto Mota (2007), 65,64 Brix, em geleia de amora-preta (Morus nigra), valor semelhante ao encontrado neste trabalho. Em geleias mistas, assim caracterizada por serem elaboradas a partir de duas frutas, abacaxi (Ananas comosus) e mamão (Carica papaya), Lago-Vanzela (2011) encontraram $70,5^{\circ}$ Brix, em que, de acordo com Santos (2012), a concentração entre 60 a 70Brix é considerada suficiente para que ocorra a geleificação da geleia durante o resfriamento.

Os valores de acidez titulável encontrados na polpa de bocaiuva são muito semelhantes aos valores obtidos no fruto noni (Morinda citrofolia) 
entre 0,30 e 0,39 g $100 \mathrm{~g}^{-1}$. Os valores reportados para geleia no presente

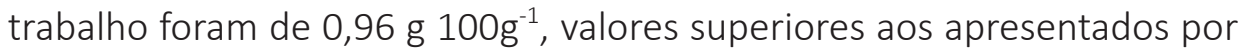
Caetano et al. (2012), em que foi avaliado que geleias com diferentes concentrações de acerola obtiveram valores entre 0,49 a 0,68 g 100g-1, Carneiro (2012), avaliando as geleias de pêssego (Prunus persica) e de morango (Fragaria vesca) obtiveram os teores de 0,48 g100g-1 e 0,82 g 100g ${ }^{1}$, respectivamente, sendo a geleia de morango a que melhor se aproxima dos valores da geleia deste trabalho.

A polpa de bocaiuva apresentou $0,33 \mathrm{~g} 100 \mathrm{~g}^{-1}$ de ácido cítrico e $\mathrm{pH}$ de 5,75 enquanto a adição do suco de maracujá na geleia reduziu o $\mathrm{pH}$ para 3,7 e aumentou a acidez $\left(0,96 \mathrm{~g} 100 \mathrm{~g}^{-1}\right.$ de ácido cítrico). De acordo com Magro et al. (2006), produtos com alto teor de acidez apresentam melhor conservação, devido à minimização do desenvolvimento de microrganismos (MAGRO et al., 2006). De acordo com Jackix (1988), a redução do pH na elaboração da geleia, por meio da adição de acidulantes, tem por finalidade a geleificação da pectina em meio com elevada concentração de açúcar. A acidez total da geleia deve estar entre 0,5 a 0,8\%, quando acima de $1 \%$, ocorre sinérese, o que não ocorreu neste trabalho. Os acidulantes naturais do suco de maracujá corrigiram o pH levando a formação de gel.

A atividade de água da geleia permaneceu entre 0,84 $\pm 0,021$. De acordo com Gava (2004), a presença do açúcar eleva a pressão osmótica do meio e, por conta disso, a atividade de água do produto acaba sendo diminuída. Ainda por conta do conteúdo de açúcar presente no alimento, a camada de água que protege as moléculas de pectina é removida, ação que possibilita a formação do gel pectina-açúcar, o que resulta em condições desfavoráveis para o crescimento de bolores, bactérias e leveduras. Sabe-se ainda, que esses microrganismos apresentam uma baixa resistência térmica e raramente estão relacionados a processos de deterioração de produtos que passaram por algum tipo de tratamento térmico (TOREZAN; PEZOA, 2000).

Em referência aos sólidos totais, a polpa de bocaiuva apresentou valores muito superiores aos encontrados em uva, cupuaçu, acerola e cajá de 20\%, 10,3, 9,1 e 8,1 (BUENO et al., 2002). Em geleia de umbu-cajá, os valores de sólidos totais variaram de 57,58 a 62,13\% (OLIVEIRA et al.,2014), sendo esses valores superiores ao reportado no presente estudo $(52,56 \%)$. 
A avaliação de sólidos totais é um fator de extrema importância, pois está correlacionada com a umidade do produto e consequentemente com a perecibilidade deste.

Os resultados obtidos para fenóis totais, atividade antioxidante, taninos e carotenoides totais da polpa in natura e da geleia tradicional podem ser visualizadas na Tabela 2.

Tabela 2 - Compostos bioativos em geleia de bocaiuva com maracujá. Resultados obtidos a partir de média e desvio padrão

\begin{tabular}{lccccc}
\hline & $\begin{array}{c}\text { Fenois } \\
\text { (mg ácido } \\
\text { gálico } \\
\text { /g de fruta) }\end{array}$ & $\begin{array}{c}\text { Atividade } \\
\text { antioxidante } \\
\text { (IC50 expresso em } \\
\text { g de amostra/g de } \\
\text { DPPH) }\end{array}$ & $\begin{array}{c}\text { Taninos } \\
\text { (mg de } \\
\text { taninos/ 100g } \\
\text { de amostra) }\end{array}$ & $\begin{array}{c}\text { Carotenoides } \\
\text { (mg/100g) }\end{array}$ & $\begin{array}{c}\text { Ascórbido } \\
\text { ác. ascórbico/ } \\
\text { 100g de } \\
\text { amostra) }\end{array}$ \\
\hline $\begin{array}{l}\text { Polpa de } \\
\text { bocaiuva }\end{array}$ & $240,8 \pm 38,8$ & $261,14 \pm 35,51$ & $10,66 \pm 1,1926$ & $58,29 \pm 6,99$ & $1,42 \pm 0,091$ \\
$\begin{array}{l}\text { Geleia de } \\
\text { bocaiuva } \\
\text { maracujá }\end{array}$ & $106,01 \pm 20$ & $466,55 \pm 37,43$ & $4,94 \pm 0,103$ & $11,44 \pm 0,87$ & $0,89 \pm 0,09$ \\
\hline
\end{tabular}

*Dados apresentados em média \pm desvio-padrão.

Fonte: Elaborado pelo autor.

A polpa de bocaiuva apresenta $240,8 \mathrm{mg} \mathrm{g}^{-1}$ de fenóis totais, valor aproximado ao encontrado em frutos de noni (Morinda citrifolia Linn.) (287,60 mg EAG), por Coimbra et al. (2017), e guavira (Campomanesia sp.) (259 mg EAG), por Rocha et al (2011), e superior aos obtidos em cajá-manga (Spondias dulcis), 160,0 mg EAG), por Coimbra et al. (2017). Os teores de compostos fenólicos variam de acordo com a espécie, condições climáticas, maturação e outros. O processamento e a estocagem de alimentos podem afetar o conteúdo e a biodisponibilidade desses componentes (MELO et al., 2008), o que pode explicar o decréscimo desse conteúdo na geleia, devido à diluição dos compostos em função do acréscimo de açúcar. No entanto a geleia apresentou $106,01 \mathrm{mg} \mathrm{g}^{-1}$ de fenóis totais, valor significativo para produto processado, indicando que ocorreu retenção desses compostos após o processamento.

Estudos indicam que a correlação entre fenóis totais e a capacidade antioxidante pode depender do método de determinação escolhido e 
também das características hidrofóbicas ou hidrofílicas do sistema teste e dos antioxidantes testados (ROESLER et al., 2007). A polpa de bocaiuva apresentou atividade antioxidante de $261,14 \mathrm{mg} \mathrm{mL}^{-1}$, sendo que Roesler et al. (2007) encontraram 298,75 $\mathrm{mg} \mathrm{mL}^{-1}$. É importante ressaltar que, na análise de Roesler (2007), as frutas foram avaliadas com a casca, e não somente a polpa isolada. Para Donadon et al. (2016), a capacidade antioxidante da polpa de bocaiuva in natura obteve um IC50 de 196,75 em g de amostra $\mathrm{g}^{-1}$ de DPPH, resultado abaixo dos valores encontrados neste trabalho. Verificase que o processamento levou à redução da atividade antioxidante, mas a geleia continua apresentando capacidade de sequestrar radicais livres.

Os resultados de taninos obtidos na polpa de bocaiuva (10,66 mg $100 \mathrm{~g}^{-1}$ ) se assemelham aos encontrados por Rocha et al. (2011) na fruta cagaita (Eugenia dysenterica) entre 7 e $4 \mathrm{mg} 100 \mathrm{~g}^{-1}$, sendo este último valor muito próximo ao apresentado na geleia de bocaiuva com maracujá, fato este que é bastante expressivo, afinal, comparando valores de um produto com os de uma fruta in natura, é possível dizer que, mesmo após o processo de cocção, os valores permanecem significativos.

Os teores de carotenoides totais obtidos na polpa e geleia de bocaiuva

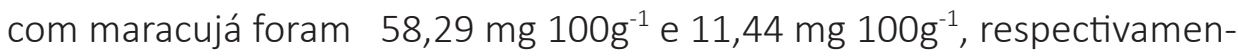
te. Os valores encontrados por Jorge et al. (2013) em geleia de pimentão vermelho com pimenta dedo de moça (C. baccatum var.Pendulum) foram

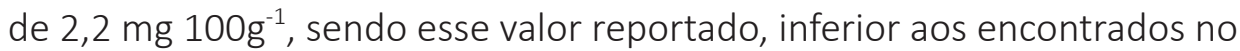
presente estudo. O estudo de Lima et al. (2007) apresentou valor de 7,25 mg $100 \mathrm{~g}^{-1}$ de carotenoides totais na polpa do pequi. Já o estudo de Godoy e Rodrigues-Amaya (1994), 16,7 mg 100 $\mathrm{g}^{-1}$ em polpa de buriti. De acordo com Costa et al. (2012), a quantidade de carotenoides totais encontrados no extrato seco da polpa de bocaiuva foi de $538 \mathrm{mg} \mathrm{g}^{-1}$, enquanto o óleo da polpa de bocaiuva obteve o teor de $694 \mathrm{mg} \mathrm{g}^{-1}$.

Em relação aos valores encontrados de ácido ascórbico, a quantidade obtida na amostra de polpa de bocaiuva $(1,42 \mathrm{mg} / 100 \mathrm{~g})$ mostrou-se abaixo dos resultados expressados por Sanjinez-Argandoña e Chuba (2011), 11,46 mg $100 \mathrm{~g}^{-1}$ na polpa de bocaiuva. Sabe-se que diversos fatores afetam a estabilidade do ácido ascórbico durante o armazenamento, incluindo o $\mathrm{pH}$ do meio, a presença de oxigênio e de íons metálicos, e a temperatura 
(SPINOLA et al., 2013). O processamento da bocaiuva em polpa pode ter levado à redução do teor de ácido ascórbico. No trabalho de Silva, Lopes e Valente-Mesquita (2006), os resultados mostraram que tanto a adição de sacarose quanto o tratamento térmico influenciaram significativamente o teor de ácido ascórbico; assim, podemos concluir que o baixo valor encontrado neste trabalho pode ser atribuído ao tempo e condições de armazenamento da polpa, à adição de sacarose e ao tratamento térmico aplicados no desenvolvimento da geleia.

De acordo com Rotili et al. (2013), o maracujá recém-colhido apresenta aproximadamente $31 \mathrm{mg}$ EAA $100 \mathrm{~mL}^{-1}$ de DPPH, $20 \mathrm{mg}$ EAG $100 \mathrm{~mL}^{-1}$

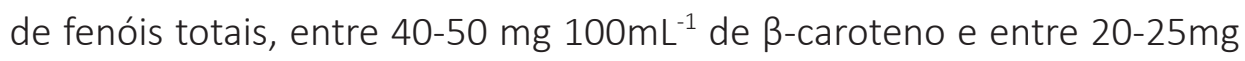
$100 \mathrm{~mL}^{-1}$ de ácido ascórbico. A retenção de fenóis totais, taninos, ácido ascórbico e carotenoides na geleia de bocaiuva com maracujá pode ser proveniente da combinação polpa de bocaiuva e suco de maracujá. Optouse por caracterizar somente a polpa de bocaiuva nesta pesquisa devido aos diferentes morfotipos de bocaiuva encontrados no estado de Mato Grosso do Sul, com diferentes tonalidades de polpa e composição.

\section{CONCLUSÕES}

A geleia de bocaiuva com maracujá apresenta 106,01 $\mathrm{mg} \mathrm{g}^{-1}$ de ácido

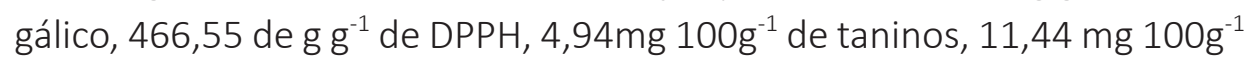
de carotenoides. A polpa de bocaiuva apresenta $240,8 \mathrm{mg} \mathrm{g}^{-1}$ de ácido gálico, 261,14 de $\mathrm{g} \mathrm{g}^{-1}$ de DPPH, 10,66 mg 100 g $\mathrm{g}^{-1}$ de taninos e 58,29 mg 100 $\mathrm{g}^{-1}$ de carotenoides. A geleia de bocaiuva com maracujá reteve os compostos considerados bioativos em sua composição, provenientes das polpas de bocaiuva e de maracujá.

\section{REFERÊNCIAS}

ASSOCIATION OF OFFICIAL ANALYTICAL CHEMISTS (AOAC). Official methods of analysis of the Association of Official Analytical Chemists International. 16. ed. Washington: Ed. Patrícia Cunniff, 1997. V. 2.

BRASIL. Agência Nacional de Vigilância Sanitária. Resolução - CNNPA n. 12, de 1978, Regulamento técnico sobre os padrões microbiológicos para alimentos. 
Disponível em: http://www.anvisa.gov.br/component/k2/item/199?ltemid=294. Acesso em: 20 ago. 2017.

BRASIL. Ministério da Agricultura, Pecuária e Abastecimento. Métodos analíticos oficiais físico-químicos, para controle de leite e produtos lácteos. Instrução Normativa n. 68, de 12 de dezembro de 2006. Diário Oficial da União, Brasília, Seção 1, de 14 de dezembro de 2006.

BRESSAN, J.; HERMSDORFF, H. H. M.; ZULET, M. A. Impacto hormonal e inflamatório de diferentes composições dietéticas: ênfase em padrões alimentares e fatores dietéticos específicos. Arquivos Brasileiros de Endocrinologia \& Metabologia, São Paulo, v. 53, n. 5, p. 572-81. 2009.

BUENO, S. M. et al. Avaliação da qualidade de polpas de frutas congeladas. Revista Instituto Adolfo Lutz, São Paulo, v. 62, n. 2, p. 121-6, 2002.

CAETANO, P. K. et al. Características físico-químicas e sensorial de geleia elaborada com polpa e suco de acerola. Brazilian Journal of Food Technology, Campinas, v. 15, n. 3, p.191-7, 2012

CARNEIRO, A. P. de G. et al. Caracterização físico-química dos frutos in natura e geleia de morango e pêssego, e aspectos de rotulagem do produto ao consumidor. Revista Brasileira de Produtos Agroindustriais, Campina Grande, v. 14, n. 3, p. 295-8, 2012.

COIMBRA, P. da S. et al. Compostos fenólicos e atividade antioxidante de polpa de frutos de cajá- manga (Spondias dulcis) e noni (Morinda citrofolia). In: SIMPÓsIO DE FRUTOS NATIVOS E EXÓTICOS, 2., 2017. Campo Grande, MS. Anais [...] Campo Grande, MS: UFMS. p. 77-80, 2017.

COSTA, G. L. A. Avaliação do potencial mutagênico, antimutagênico e antioxidante do óleo da polpa de Acrocomia aculeata (Arecaceae). Orientadora: Suzana Elisa Moreno. Dissertação (Mestrado em Biotecnologia Aplicada à Saúde) - Universidade Católica Dom Bosco, Campo Grande, MS, 2012.

DONADON, J. R. et al. Processo de obtenção e avaliação química de doce cristalizado de bocaiuva. Agroecologia. Dourados, MS: Embrapa Pantanal, 2016.

GARCIA, L. G. C. et al. Geleia de buriti (Mauritia flexuosa): agregação de valor aos frutos do cerrado brasileiro. Brazilian Journal of Food Technology, Campinas, v. 20, e2016043, 2017. 
GAVA, A. J. Princípios da Tecnologia de Alimentos. 2. ed. São Paulo: Nobel, 2004.

GODOY, H. T.; RODRIGUEZ-AMAYA, D. B. Occurrency of cis-Isomers of provitamin A in brazillian fruits. Journal Agricultural Food Chemistry, Easton, v. 42, p. 130613, 1994.

JACKIX, M. H. Doces, geleias e fruta em calda: teórico e prático. 2. ed. São Paulo: Editora da Unicamp, 1988. 98 p.

JORGE, L. Desenvolvimento de geleia de pimentão com pimenta, visando à elaboração de produtos destinados ao mercado "gourmet". In: CONGRESSO INTERINSTITUCIONAL DE INICIAÇÃO CIENTíFICA, 7., 13-15 ago. 2013, Campinas. Anais [...]. Campinas: ITAL, 2013.

KIMURA, M.; RODRIGUEZ-AMAYA, D.B. A scheme for obtaining standards and HPLC quantification of leafy vegetable carotenoids. Food Chemistry, London, v. 78, p. 389-98, 2001.

LAGO-VANZELA, E. S. et al. Chemical and sensory characteristics of pulp and peel cajá-manga (Spondias cytherea Sonn.) jelly. Ciência e Tecnologia de Alimentos, Campinas, v. 31, n. 2, p. 398-405, 2011.

LIMA, A. de et al . Composição química e compostos bioativos presentes na polpa e na amêndoa do pequi (Caryocar brasiliense Camb.). Revista Brasileira de Fruticultura, Jaboticabal, v. 29, n. 3, p. 695-8, 2007.

MAGRO, N. G. D. et al. Comparação físico-química de frutos congelados de Butiá Erios patha (Mart.) Becc. do Paraná e Santa Catarina - Brasil. Revista Varia Scientia, Cascavel, v. 6, n. 11, p. 33-42, 2006.

MELO, E. A. et al. Capacidade antioxidante de frutas. Revista Brasileira de Ciências Farmacêuticas, São Paulo, v. 44, n. 2, p. 193-201, abr./jun., 2008

MOTA, R. V. Características químicas e aceitabilidade de geleias de amora-preta de baixo teor de sólidos solúveis. Brazilian Journal of Food Technology, Campinas, v. 10, n. 2, p. 116-21, 2007.

OLIVEIRA, E. N. A. de. et al. Estabilidade de geleias convencionais de umbucajá durante o armazenamento em condições ambientais. Revista Brasileira de Engenharia Agrícola e Ambiental, Campina Grande, v. 18, n. 3, p. 329-37, 2014. 
PEREIRA, et al. Avaliação sensorial de geleia de marmelo 'Japonês' em diferentes concentrações de sólidos solúveis totais. Brazilian Journal of Food Technology, Campinas, v. 14, n. 3, p. 226-231, jul./set. 2011.

ROCHA, W. S. et al. Compostos fenólicos totais e taninos condensados em frutas nativas do cerrado. Revista Brasileira de Fruticultura, Jaboticabal, SP, v. 33, n. 4, p. 1215-21, dez. 2011.

RANGANNA, S. Manual of Analysis of Fruit and Vegetable Products. New York: McGraw-Hill, 1977.

RODRIGUEZ-AMAYA, D. B. A guide to carotenoid analysis in foods. Washington: Internacional Life Sciences Institute Press, 64. p. 2001.

ROESLER, R. et al. Atividades Antioxidante de frutas do Cerrado. Ciência e Tecnologia de Alimentos, Campinas, v. 27, n. 1, p. 53-60, jan./mar. 2007.

ROTILI, M. C.; COUTRO, S.; CELANT, V. M.; VORPAGEL, J. A.; BARP, F. K.; SALEBE, A. B.; BRAGA, G.C. Composição, atividade antioxidante e qualidade do maracujá amarelo durante armazenamento. Semina: Ciências Agrárias, Londrina, v. 34, n. 1, p. 227-40, 2013.

SANTOS. R. G. S. Geleia de cagaita (Eugenia dysenterica DC.): desenvolvimento, caracterização-microbiológica, sensorial, química e estudo da estabilidade. Revista do Instituto Adolfo Lutz, São Paulo, v. 71, n. 2, p. 281-90, 2012.

SARJINEZ-ARGANDONÃ, E. J; CHUBA, C. A. M. Biometrical, physical and chemical characterization of bocaiuva (Acrocomia aculeata (jacq.) Lodd. ex Mart) Palm fruits. Revista Brasileira de Fruticutura, v. 33, n. 3, Jaboticabal, set. 2011.

SILVA, P. T.; LOPES, M. L. M.; VALENTE-MESQUITA, V. L. Efeito de diferentes processamentos sobre o teor de ácido ascórbico em suco de laranja utilizado na elaboração de bolo, pudim e geléia. Ciência e Tecnologia de Alimentos, Campinas, v. 26, n. 3, p. 678-82, jul./set. 2006.

SPINOLA, V.; BERTA, B.; CÂMARA, J. S.; CASTILHO, P. C. Effect of time and temperature on vitamin c stability in horticultural extracts. UHPLC-PDA vs. Iodometric Titration as Analytical Methods. LWT - Food Science and Technology, London, v. 50, n. 2, p. 489-95, 2013.

SWAIN, T.; HILLS, W. E. The phenolic constituents of Punnus domestica. The quantitative analysis of phenolic constituents. Journal of the Science of Food and Agriculture, London, v. 19, p. 63-8, 1959. 
VIANA, E. S. et al. Caracterização físico-química e sensorial de geleia de mamão com araçá-boi. Revista Brasileira de Fruticultura, Jaboticabal, SP, v. 34, n. 4, p. 1154-64, dez., 2012.

TOREZAN, G. A. P.; PEZOA, G. N. H. Produção de geleia de manga através de processo contínuo de fabricação, rica em sólidos da fruta e sem adição de açúcares. In: CONGRESSO BRASILEIRO DE CIÊNCIA E TECNOLOGIA DE ALIMENTOS, 17., Fortaleza, CE, ago. 2000, Resumos [...]. Fortaleza: Sociedade Brasileira de Ciência e Tecnologia de Alimentos, p. 11.136, 2000. V. 4.

ZENEBON, O.; PASCUET, N. S.; TIGLEA, P. Métodos físico-químicos para análise de alimentos. São Paulo: Instituto Adolfo Lutz, 2008. 